\title{
Effects of flow balancing on active magnetic regenerator performance
}

\author{
Eriksen, Dan; Engelbrecht, Kurt; Bahl, Christian; Bjørk, Rasmus; Nielsen, Kaspar Kirstein
}

Published in:

Applied Thermal Engineering

Link to article, DOI:

10.1016/j.applthermaleng.2016.03.001

Publication date:

2016

Document Version

Peer reviewed version

Link back to DTU Orbit

Citation (APA):

Eriksen, D., Engelbrecht, K., Bahl, C., Bjørk, R., \& Nielsen, K. K. (2016). Effects of flow balancing on active magnetic regenerator performance. Applied Thermal Engineering, 103, 1-8.

https://doi.org/10.1016/j.applthermaleng.2016.03.001

\section{General rights}

Copyright and moral rights for the publications made accessible in the public portal are retained by the authors and/or other copyright owners and it is a condition of accessing publications that users recognise and abide by the legal requirements associated with these rights.

- Users may download and print one copy of any publication from the public portal for the purpose of private study or research.

- You may not further distribute the material or use it for any profit-making activity or commercial gain

- You may freely distribute the URL identifying the publication in the public portal

If you believe that this document breaches copyright please contact us providing details, and we will remove access to the work immediately and investigate your claim. 


\title{
Effects of flow balancing on active magnetic regenerator performance
}

\author{
D. Eriksen, K. Engelbrecht, C.R.H. Bahl, R. Bjørk, K.K. Nielsen \\ Department of Energy Conversion and Storage \\ Technical University of Denmark \\ Frederiksborgvej 399, 4000 Roskilde, Denmark
}

\begin{abstract}
Experiments with a recently constructed rotary multi-bed active magnetic regnenerator (AMR) prototype have revealed strong impacts on the temperature span from variations in the resistances of the flow channels carrying heat transfer fluid in and out of the regenerator beds. In this paper we show through numerical modeling how unbalanced flow in the beds decreases the cooling power and COP for a dual bed device. Furthermore, it is shown how resistance variations in multi-bed devices give rise to unbalanced flow in the individual beds and how this decreases cooling powers and COPs of the machines by approximately $30 \%$ and $50 \%$, respectively.
\end{abstract}

Keywords: Magnetic refrigeration; Regenerator, Flow unbalance; 


\section{Introduction}

As a promising alternative to conventional vapor compression refrigeration with a potential for high efficiency, magnetic cooling based on active magnetic regenerators (AMRs) is moving closer to a possible commercialization. This is reflected in an increasing number of reported prototypes with improving performance over the recent years, see e.g. (1).

An AMR consists of a porous matrix of magnetocaloric material (MCM) undergoing an AMR cycle, which consists of subsequent magnetization and demagnetization. Combined with a reciprocating flow of a heat transfer fluid through the matrix, excess heat generated due to the magnetocaloric effect during magnetization can be rejected to a hot reservoir and a cooling load can be accepted from a cold reservoir when the matrix is demagnetized. Reciprocating devices in which a permanent magnet system and a regenerator are moved linearly with respect to each other for magnetization/demagnetization support operating conditions with a high controllability and are well suited for testing different MCMs and regenerator geometries, see e.g. (13) and (14). Reciprocating prototypes in which a regenerator and a superconducting magnetic field source are used have been presented by various groups, see e.g. (2) and (3). However, from a commercial standpoint, superconducting magnets are not (yet) viable due to price and energy consumption. Furthermore, the reciprocating motion is difficult to handle at higher operating frequencies. For these reasons the development has been towards permanent magnet designs and rotary systems. With such a system, a temperature span of $33 \mathrm{~K}$ has been demonstrated (4) with a machine using two regenerators, each with their own rotating magnet system. A promising concept for commercial machines is that of rotary multi-bed regenerators, where a compartmentalized regenerator is rotated relative to a magnet system. Multi-bed rotary regenerator devices have the advantageous possibility of utilizing the magnet for magnetizing MCM at all times, which is crucial due to the fact that the magnet is the single most expensive component in a magnetic refrigerator (7). Recently developed prototypes of this kind are using stationary regenerators and rotating magnet arrangements as this supports an energy efficient operation, see e.g. (15), (17) and (18). Such devices are indeed demonstrating improved efficiencies, see e.g. (5) and (6). However, the somewhat limited temperature span, compared to vapor compression, may suggest introducing the technology through special niche applications and concepts, see e.g. (16).

One of the main technical challenges with rotary multi-bed devices is 
the flow handling system that continuously distributes the pump-driven heat transfer fluid between the AMR and the hot and cold heat exchangers, while enabling a reciprocating flow in the regenerator beds timed with the varying magnetic field.

In a recently constructed prototype at the Technical University of Denmark (6), the flow is controlled by a system of poppet valves on the hot side of the AMR in combination with check valves on the cold side, see (8). Experiments with this prototype have revealed strong impacts on the AMR performance by small adjustments of the flow resistances of the individual regenerator flow channels, thereby affecting the balancing of the reciprocating flow in the regenerator beds (9). This issue is inherent to multi-bed rotary regenerator devices since some variations in the resistance of the flow paths through the beds will to some extend be present due to manufacturing tolerances.

In some cases, imposing a controlled unbalance in an AMR may be utilized in special configurations to improve the system performance (10). However, the unbalances in rotary multi-bed devices arising from the varying bed flow resistances are not controlled and their impact is not well understood.

In this paper we present a theoretical study based on numerical AMR modeling of the effects on system performance of unbalanced flow due to vaHrying flow resistances exemplified with experiments on the actual prototype.

\section{Experimental}

The rotary multi-bed AMR prototype considered in this paper and its heat transfer fluid flow system are illustrated in Figure 1. The device consists of a cylindrical, compartmentalized regenerator with eleven beds, containing packed spheres of $\mathrm{Gd}$ and $\mathrm{Gd}_{1-x} \mathrm{Y}_{x}, x \in\{0.025,0.05,0.10\}$ alloys as MCM. Regenerator bed dimensions with layers, particle sizes and Curie temperatures can be seen in Figure 2 and Table 1

\begin{tabular}{|c|cccc|}
\hline Layer & 1 & 2 & 3 & 4 \\
\hline$x$ & 0 & 0.025 & 0.05 & 0.10 \\
$\mathrm{~T}_{\mathrm{C}}[\mathrm{K}]$ & 291 & 287 & 283 & 272 \\
$\mathrm{~d}_{\mathrm{p}}[\mu \mathrm{m}]$ & $500-600$ & $300-500$ & $300-500$ & $300-500$ \\
\hline
\end{tabular}




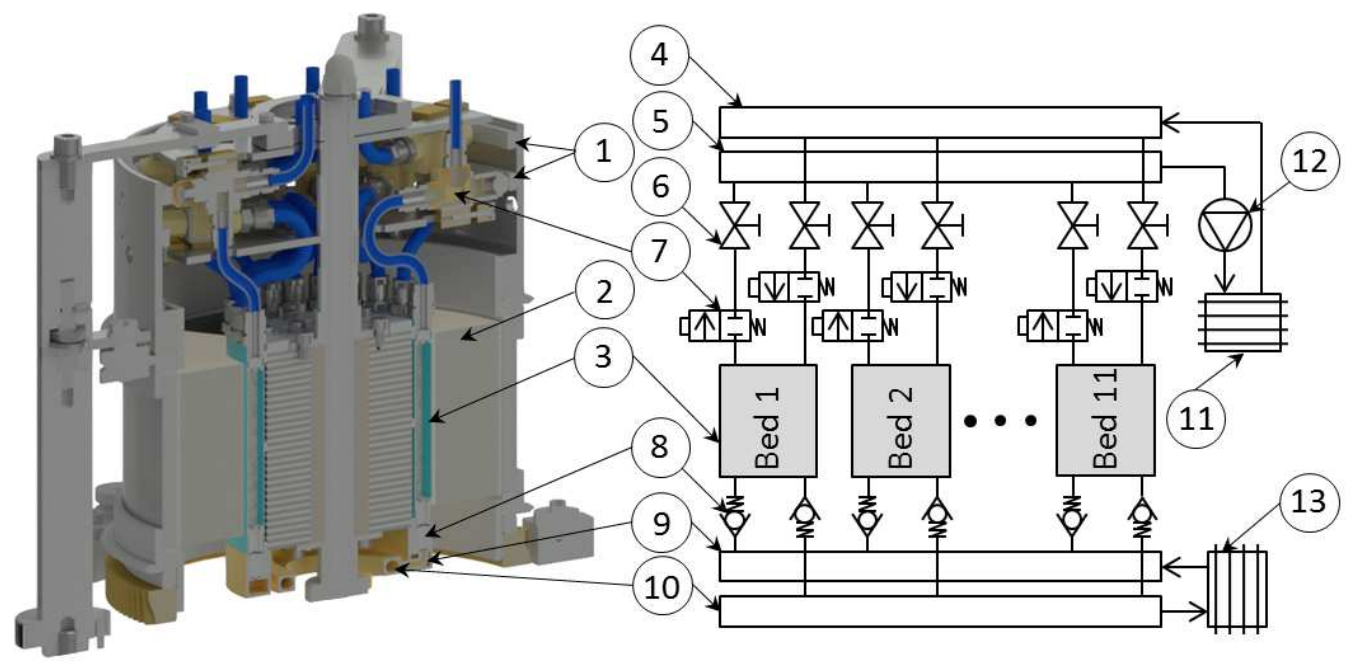

Figure 1: Cross sectional view of rotary prototype (left) and fluid flow diagram (right). Numbers refer to: Rotating cam rings (1), rotating magnet (2), regenerator bed (3), manifold, hot inlet (4), manifold, hot outlet (5), adjustment valve (6), poppet valve (7), check valve, (8), manifold, cold inlet (9), manifold, cold outlet (10), heat exchanger, hot reservoir (11), pump (12) and heat exchanger, cold reservoir (13).

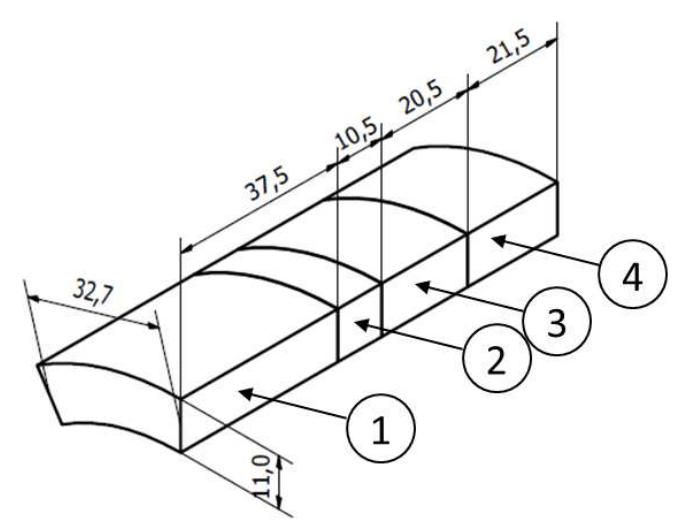

Figure 2: Layered regenerator bed geometry. Lengths are in $\mathrm{mm}$.

Table 1: Regenerator layers numbered according to Figure 2 with yttrium fractions, $x$, Curie temperatures, $\mathrm{T}_{\mathrm{C}}$, and particle diameters, $\mathrm{d}_{\mathrm{p}}$, of the $\mathrm{MCM}$ spheres. 
alloys as MCM. A Halbach-like magnet arrangement is rotated around the regenerator, which is situated on the outside of an iron core, thereby sweeping high and low field regions over the beds. Further details are given in (6). The poppet valves situated over the regenerator are connected to the beds with bent plastic hoses and each of them are connected in series with dedicated ball valves before going to the hot side manifolds. The beds are hydraulically connected in parallel with three to four beds being open to flow in each direction at all times. This means that each bed interacts with three other beds from a fluid flow standpoint in both flow directions. Since the device is a one-off construction, plastic hoses with slightly different lengths and bends are used as connectors. The check valves ensuring a unidirectional flow through the cold heat exchanger are installed in a compact component containing the cold inlet and outlet manifolds. Due to manufacturing tolerances, small variations in the flow resistances through the different beds, valve arrangements and connectors in both directions will be present. It is, however, possible to compensate for this via the adjustment valves.

During an experiment illustrating this, the prototype was operating with all

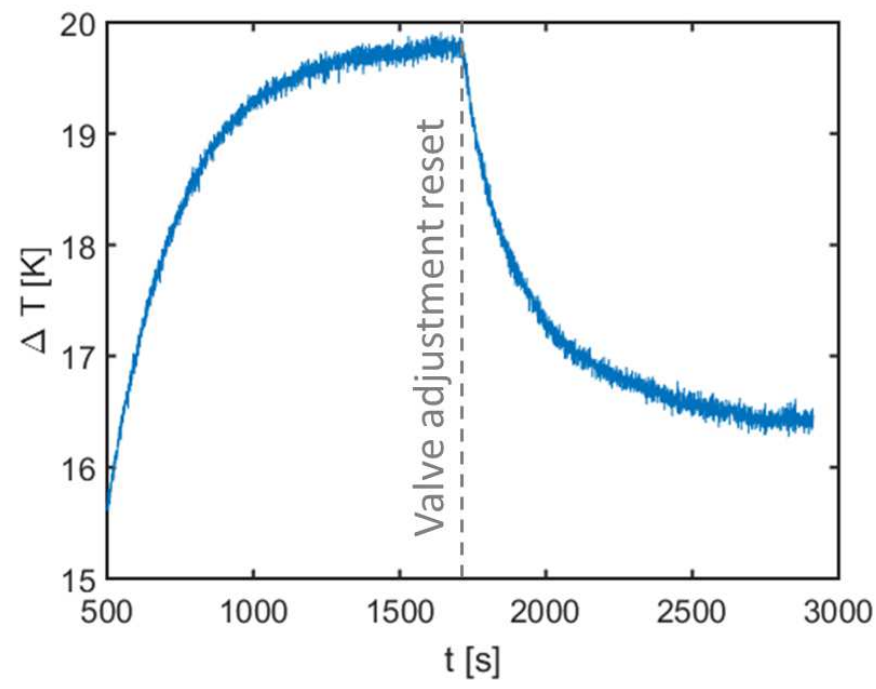

Figure 3: Effect on temperature span of resetting the adjustment valve in the cold-to-hot direction of bed 4 .

adjustment valves fully open. Then, the one in the cold-to-hot direction of 
bed number four was incrementally closed, until the temperature span, $\Delta T$, was maximized. Whith this setting, an experiment resulting in the temperature span shown in Figure 3 was carried out. After reaching $\Delta T=19.8$ $\mathrm{K}$, the valve adjustment was reset, resulting in a rather dramatic decrease in the span down to $\Delta T=16.4 \mathrm{~K}$. We expect this effect to be due to unbalanced flow in the regenerator beds, resulting from the variations in the flow resistances described above.

\section{Modeling AMRs with flow unbalance}

To investigate the effect on AMR performance of flow unbalance, a system comprising only two coupled regenerator beds, such as the one presented by (11), is first considered; see Figure 4.

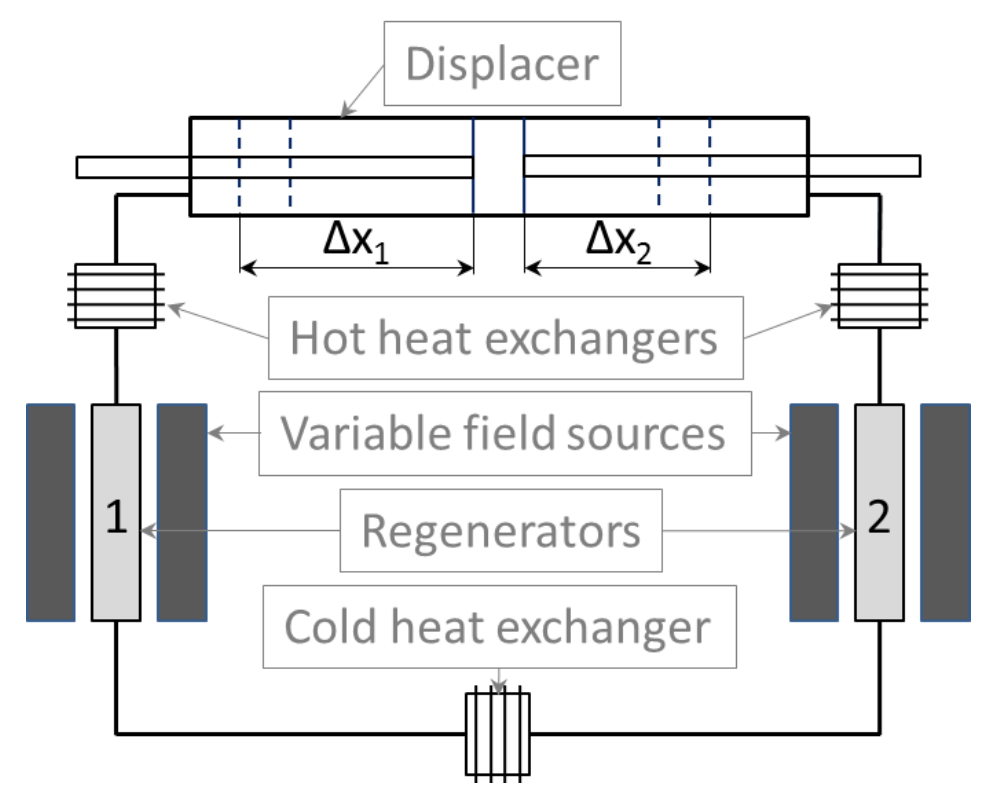

Figure 4: Schematics of an AMR system with two coupled regenerators, similar to (11).

In such a system, two regenerator beds are magnetized and demagnetized in opposite phases by dedicated variable field sources. A heat transfer fluid is being displaced, such that the demagnetized bed experiences a hot-to-cold blow while the magnetized bed is subjected to a cold-to-hot blow, see figure 
4. A system using a displacer cannot experience flow unbalance due to the flow system design. However, adding additional regenerator beds is difficult. If the beds are instead connected to a pump that operates continuously the flow in each bed in each direction is not necessarily equal. However, the displacement may be unbalanced, in which case $\Delta x_{1} \neq \Delta x_{2}$ in Figure 4 . The flow-wise series coupling of the two beds implies due to continuity, that the volume of the hot-to-cold blow in bed one, $V_{\mathrm{HC}, 1}$, equals that of the coldto-hot blow in bed two, $V_{\mathrm{CH}, 2}$. Likewise, the volume of the hot-to-cold blow through bed two, $V_{\mathrm{HC}, 2}$ equals that of the cold-to-hot blow of bed one, $V_{\mathrm{CH}, 1}$. The average absolute displacement during one AMR cycle in the beds is then

$$
V_{\mathrm{avg}}=\frac{V_{\mathrm{HC}, 1}+V_{\mathrm{CH}, 1}}{2}=\frac{V_{\mathrm{HC}, 2}+V_{\mathrm{CH}, 2}}{2} .
$$

From this we define the unbalance, $u$, in each of the two beds as the volume displacement in the hot-to-cold direction minus that in the cold-to-hot direction, relative to their average:

$$
\begin{aligned}
& u_{1}=\frac{V_{\mathrm{HC}, 1}-V_{\mathrm{CH}, 1}}{V_{\mathrm{avg}}}, \\
& u_{2}=\frac{V_{\mathrm{HC}, 2}-V_{\mathrm{CH}, 2}}{V_{\mathrm{avg}}}=-u_{1} .
\end{aligned}
$$

The influence of this unbalance parameter on the AMR performance has been analyzed by the use of a 1D numerical AMR model, based on (12).

In this model a single regenerator in which a flow unbalance may be present is considered. The model solves energy balance equations for the heat transfer fluid and the solid porous MCM matrix respectively. The governing equation, considering volume specific energies in an infinitesimal control volume of length $d x$ and cross sectional area, $A_{\mathrm{c}}$, for the fluid, may be formulated as:

$$
\frac{\dot{m} c_{\mathrm{f}}}{A_{\mathrm{c}}} \frac{\partial T_{\mathrm{f}}}{\partial x}+h a_{\mathrm{s}}\left(T_{\mathrm{f}}-T_{\mathrm{s}}\right)+\rho_{\mathrm{f}} \epsilon c_{\mathrm{f}} \frac{\partial T_{\mathrm{f}}}{\partial t}-k_{\mathrm{disp}} \frac{\partial^{2} T_{\mathrm{f}}}{\partial x^{2}}=\frac{\dot{m}}{\rho_{\mathrm{f}} A_{\mathrm{c}}} \frac{\partial p}{\partial x} .
$$

The terms represent, from left to right, enthalpy change of the fluid, convective heat transfer from fluid to solid, energy storage, axial dispersion and viscous dissipation. $\dot{m}$ is the fluid mass flow rate (positive in the hot do cold direction), $c_{\mathrm{f}}$ is the mass specific heat capacity of the fluid, $T_{\mathrm{f}}$ and $T_{\mathrm{s}}$ are the temperatures of the fluid and solid respectively, $h$ is the convective 
heat transfer coefficient from fluid to solid, $a_{\mathrm{s}}$ is the volume specific surface area of the MCM, $\rho_{\mathrm{f}}$ is the fluid density, $\epsilon$ is the porosity, $t$ is time, $k_{\text {disp }}$ is the thermal conductivity of the fluid due to axial dispersion and $p$ is the pressure.

Likewise, the governing equation for the solid can be formulated as:

$$
h a_{\mathrm{s}}\left(T_{\mathrm{f}}-T_{\mathrm{s}}\right)+k_{\mathrm{eff}} \frac{\partial^{2} T_{\mathrm{s}}}{\partial x^{2}}=(1-\epsilon) \rho T_{\mathrm{s}}\left(\frac{\partial s_{\mathrm{m}}}{\partial B}\right)_{T} \frac{\partial B}{\partial t}+(1-\epsilon) \rho_{\mathrm{s}} c_{\mathrm{B}, \mathrm{s}} \frac{\partial T_{\mathrm{s}}}{\partial t},
$$

where the terms, from left to right, represent convective heat transfer from fluid to solid, axial conduction, transfer of magnetic work and energy storage. $k_{\text {eff }}$ is the thermal conductivity of the combined fluid/solid matrix, $B$ is the internal magnetic field, $\rho_{\mathrm{s}}$ is the density of the MCM and $c_{\mathrm{B}, \mathrm{s}}$ is the mass specific heat capacity of the MCM for fixed magnetic field.

The mass flow rate and fluid temperature entering the matrix are given as boundary conditions as functions of space, $x$, and time, $t$ :

$$
\begin{aligned}
& \dot{m}(t) \geq 0 \Rightarrow T_{\mathrm{f}}(x=0, t)=T_{\mathrm{H}} \\
& \dot{m}(t) \leq 0 \Rightarrow T_{\mathrm{f}}(x=\mathrm{L}, t)=T_{\mathrm{C}},
\end{aligned}
$$

where $T_{\mathrm{H}}$ and $T_{\mathrm{C}}$ are the temperatures of the hot and cold reservoirs respectively and $\mathrm{L}$ is the regenerator length. A linear temperature ramp between $T_{\mathrm{H}}$ and $T_{\mathrm{C}}$ is used as initial condition. The regenerator modeled in this case corresponds to one bed of the rotary prototype described above. Here, the temperature span between the hot and the cold reservoirs is set to $\Delta T=20 \mathrm{~K}$, with $T_{\mathrm{H}}=292 \mathrm{~K}$. The AMR operational frequency is $f=1 \mathrm{~Hz}$, and the average mass flow rate is $\dot{m}=1.67 \cdot 10^{-2} \mathrm{~kg} \mathrm{~s}^{-1}$. The heat transfer fluid is assumed as water mixed with $10 \%$ ethylene glycol. As properties of the MCM, data from the Weiss mean field model for Gd are used, see (7), with Curie temperatures shifted to match the $\operatorname{Gd}_{1-x} Y_{x}$ alloys. Data sets from this model are often used in modeling AMRs as this supports comparison between different models, see e.g. (19), (20) and (21).

The resulting cooling power, $\dot{Q}_{\mathrm{C}}$, and heat rejection, $\dot{Q}_{\mathrm{H}}$, in a regenerator bed as functions of the unbalance are plotted in Figure 5. When reviewing Figure 5, it is important to remember that the system is being supported by outside fluid and energy inputs to support the single regenerator operating with unbalanced flow. Systems with a negative unbalance value require a supply of fluid at $T_{\mathrm{C}}$ provided from an outside source while systems with a 


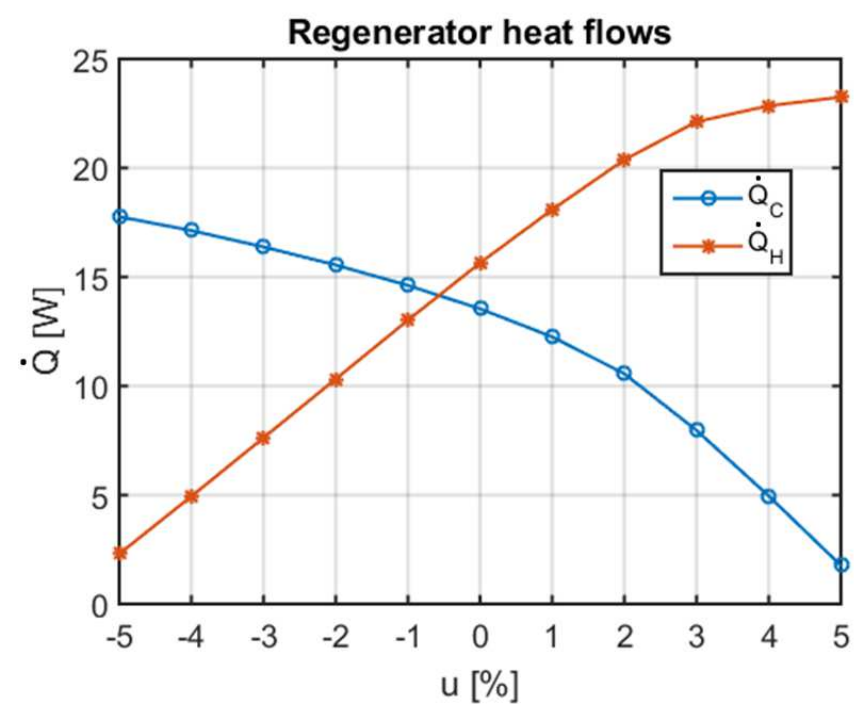

Figure 5: Cooling power and heat rejection of the modeled single regenerator versus unbalance fraction.

positive unbalance require additional fluid flow at $T_{\mathrm{H}}$ but at the same time produce an excess of fluid at $T_{\mathrm{C}}$. The assistance of an outside energy system allows regenerators with a negative unbalance to operate at efficiencies that appear higher than the Carnot limit.

A realistic modeling case is to couple a regenerator with a negative unbalance with one that has a positive unbalance. This gives the overall system an equal fluid flow in both directions and provides realistic predictions for the entire system. For the coupled system, the unbalances of the two regenerators are always of equal magnitudes and opposite signs. That is, in order to obtain the total value of $\dot{Q}_{\mathrm{C}}$ (or $\dot{Q}_{\mathrm{H}}$ ) for a given absolute value of the unbalance of the system, the values for a single bed corresponding to the positive and negative values respectively of that unbalance are added together. The results are shown in Figure 6.

From this it is clear that the cooling power is reduced by almost $30 \%$ if the system is operated at an unbalance of only $5 \%$ in the modeled case. The COP, defined as

$$
C O P=\frac{\dot{Q}_{\mathrm{C}}}{\dot{W}}=\frac{\dot{Q}_{\mathrm{C}}}{\dot{Q}_{\mathrm{H}}-\dot{Q}_{\mathrm{C}}},
$$




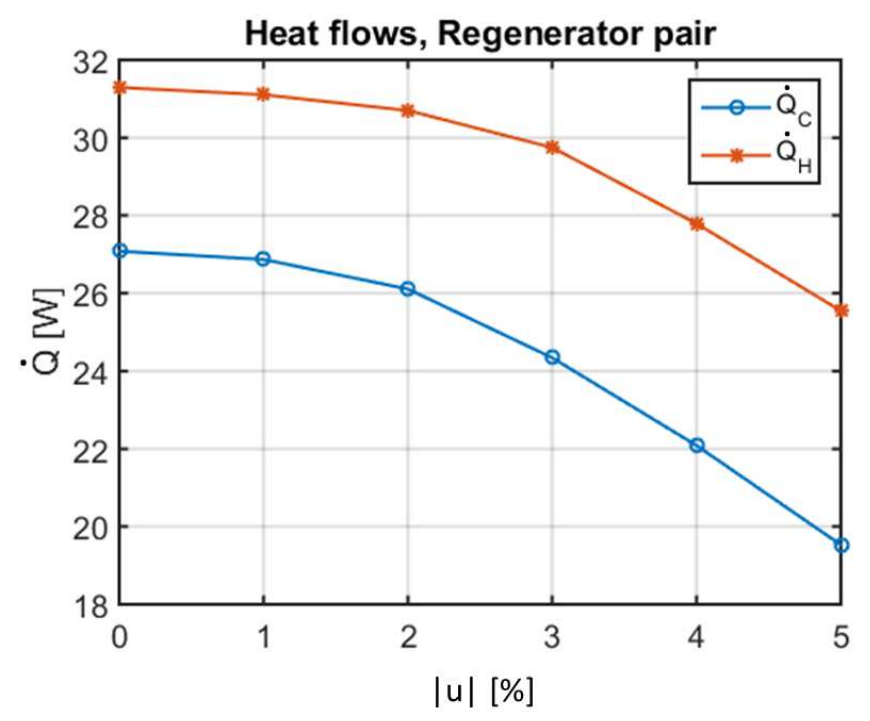

Figure 6: Cooling power and heat rejection of the modeled two bed device versus unbalance.

where $\dot{W}$ is the total work input to the system, as a function of the unbalance is plotted in figure 7 . In this case, an unbalance of $5 \%$ reduces the COP with almost $50 \%$.

\subsection{Effects on temperature profile of flow unbalance}

To illustrate the effects of flow unbalance on the AMR cycle, the temperature profiles in the MCM of three example operating conditions with different unbalances are plotted in Figure 8. The wavy nature of the solid temperature profile is caused by concentrations of high specific heat and entropy change associated with the layered bed. In the figure, the profile is plotted at the middle of the hot-to-cold flow period as a representative snapshot of the AMR operation. Here, the modeled flow profile, i.e. flow rate vs. time, is trapezoidal, corresponding to the flow model used in section 4 for the rotary multi-bed case. Full videos that show fluid and MCM temperatures throughout a single cycle operating at cyclical steady state are available as supporting material.

Figure 8 shows that flow unbalance drastically affects the temperature profile in the regenerator. When the flow is unbalanced in the positive di- 


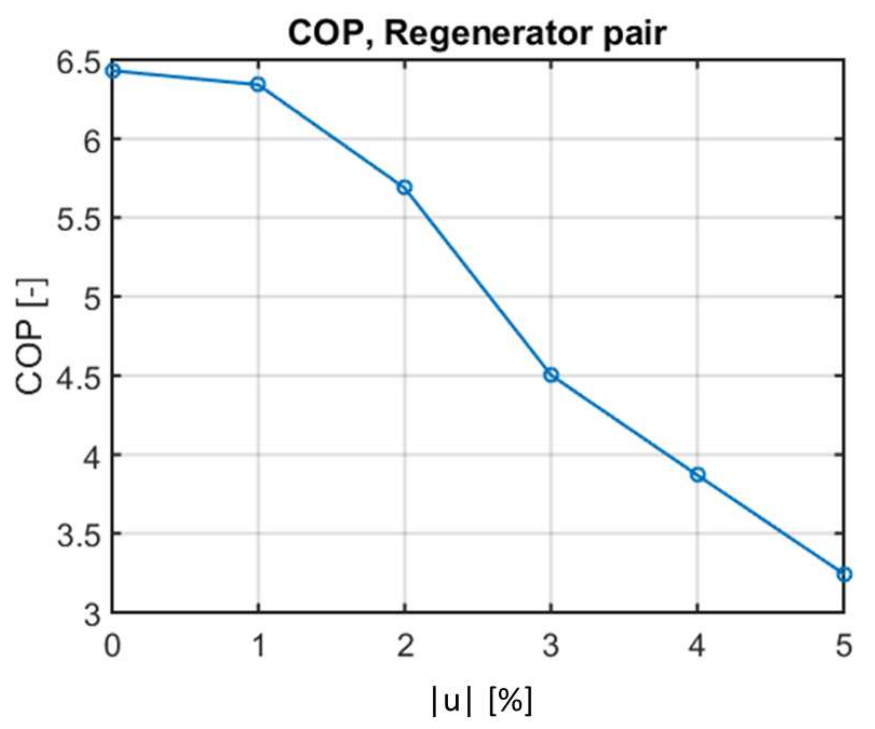

Figure 7: COP of the modeled two bed device versus unbalance .

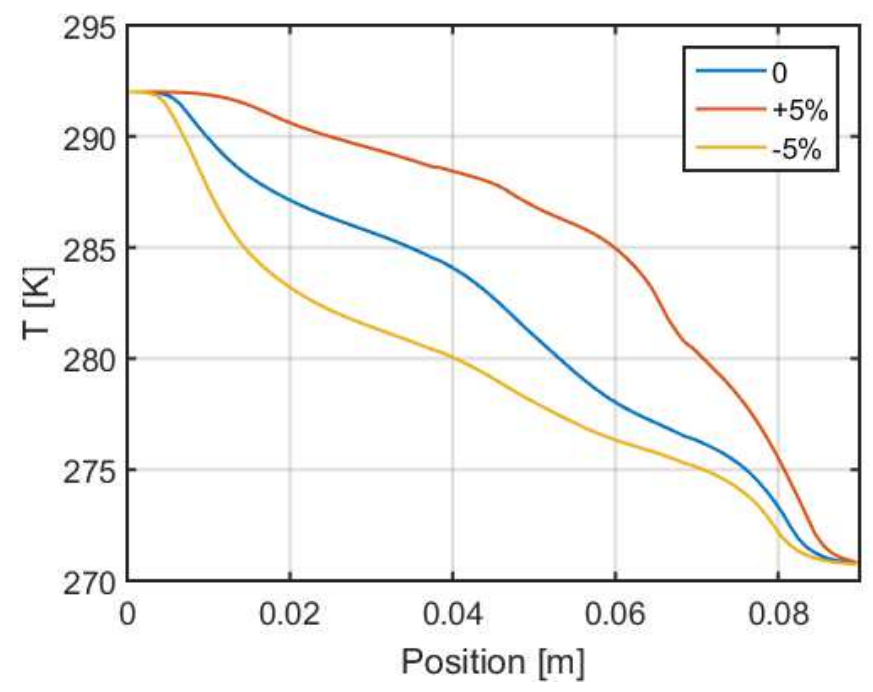

Figure 8: Solid material temperature profile at the middle of the hot-to-cold flow period for three values of the unbalance. 


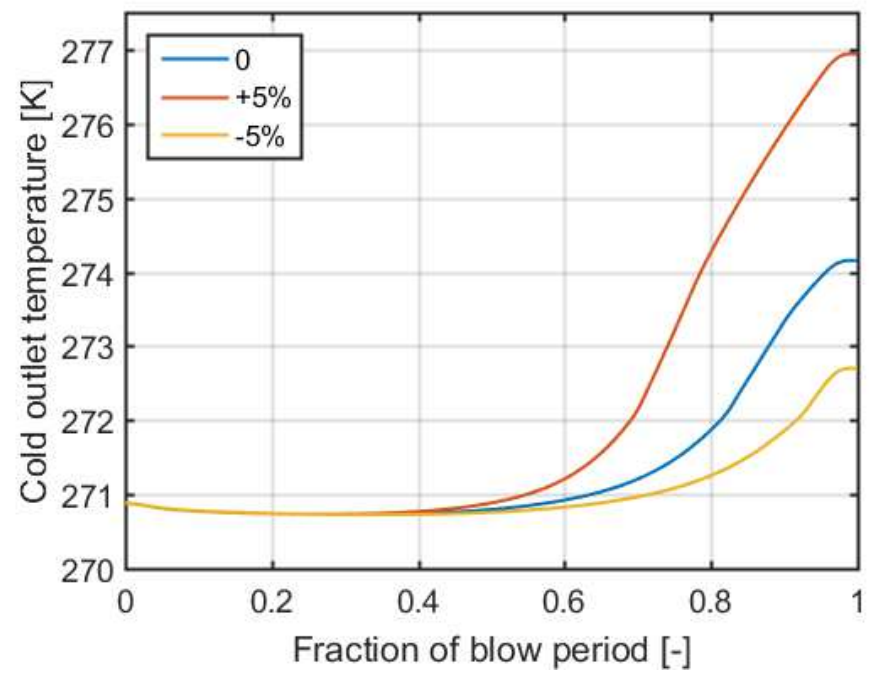

Figure 9: Temperature of fluid exiting the cold end of the regenerator during the hot to cold blow.

rection, the temperature of the regenerator increases throughout the interior of the regenerator and its ability to accept a cooling load is greatly reduced, mostly due to the fact that the fluid exiting the cold end is above the cold reservoir temperature for a portion of the cycle. On the other hand, the regenerator with a negative unbalance is cooler in the interior and is much more capable of accepting a cooling load. The reason the performance is so influenced by flow unbalance is that the enhanced cooling of the negative unbalance beds is only possible when the excess fluid at $T_{\mathrm{C}}$ is provided by the regenerator bed with a positive unbalance. In the modeled case, the regenerators are all working between the same hot and cold reservoirs, i.e. the fluid inlet temperature is $T_{\mathrm{H}}$ at the hot side and $T_{\mathrm{C}}$ at the cold side in all cases. What is varying as a function of flow unbalance is the fluid exit temperatures - and this is what causes the different values of $\dot{Q}_{\mathrm{C}}$ and $\dot{Q}_{\mathrm{H}}$. This is also evident from Figure 9, where the temperature of the fluid exiting the cold end of the regenerator is plotted for the entire hot to cold blow period. In this case it can be seen, that the exit temperature actually gets above the cold reservoir temperature of $272 \mathrm{~K}$ at the end of the blow period in all cases. However, the average between the exiting temperatures of the positive 
and the negative unbalanced beds is higher than that of the balanced bed. Therefore, two coupled beds perform better with no unbalance. 


\section{Rotary multi-bed flow model}

In order to analyse the unbalance effects on the performance of a multibed AMR machine that may arise from variations in the flow resistances of the different beds/flow paths that are operated in varying combinations, a simple flow model has been set up.

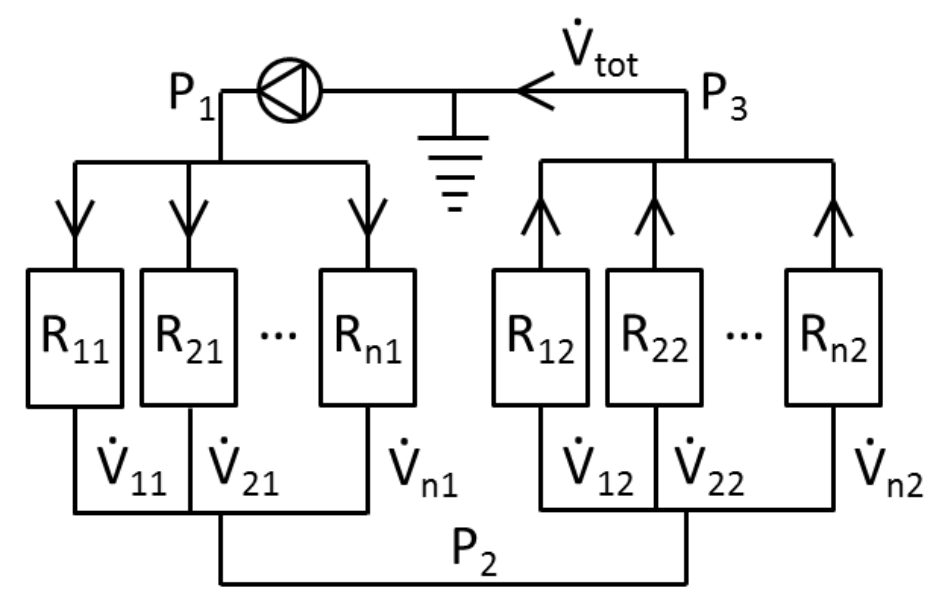

Figure 10: Schematic diagram representing the flow circuit of a multi-bed AMR machine with $n$ beds corresponding to the rotary prototype illustrated in Figure 1. The resistances, $R_{i j}$ refer to bed $i$ including corresponding valves and fittings in the direction $j$, with $j=1$ denoting the hot-to-cold and $j=2$ the cold-to-hot direction.

As indicated in Figure 10, the flow system of a multi-bed prototype is treated as a circuit in which the flow channels from hot to cold (index $j=1$ ) and from cold to hot (index $j=2$ ) each have different resistances, $R_{i j}$. In the case of the prototype illustrated in Figure 1, $R_{11}$ is the sum of the resistances of an adjustment valve, a poppet valve, regenerator bed 1 in the hot to cold direction, a check valve and the connecting hoses and fittings. The resistances, $R_{i j}$ are modeled as Ohmic. They are functions of the rotational angle, $\phi$, of the magnet/cam rings, that open/close the poppet valves linearly. That is, the rotational angle normalized with the angle of a full AMR cycle, $\phi^{*}=\phi / \phi_{\mathrm{AMR}}$, can be divided into parts taken up by flow pauses, $\phi_{\mathrm{p}}^{*}$, ramps, $\phi_{\mathrm{r}}^{*}$ and full flow, $\phi_{\mathrm{f}}^{*}$, that all together add up to one for a complete 


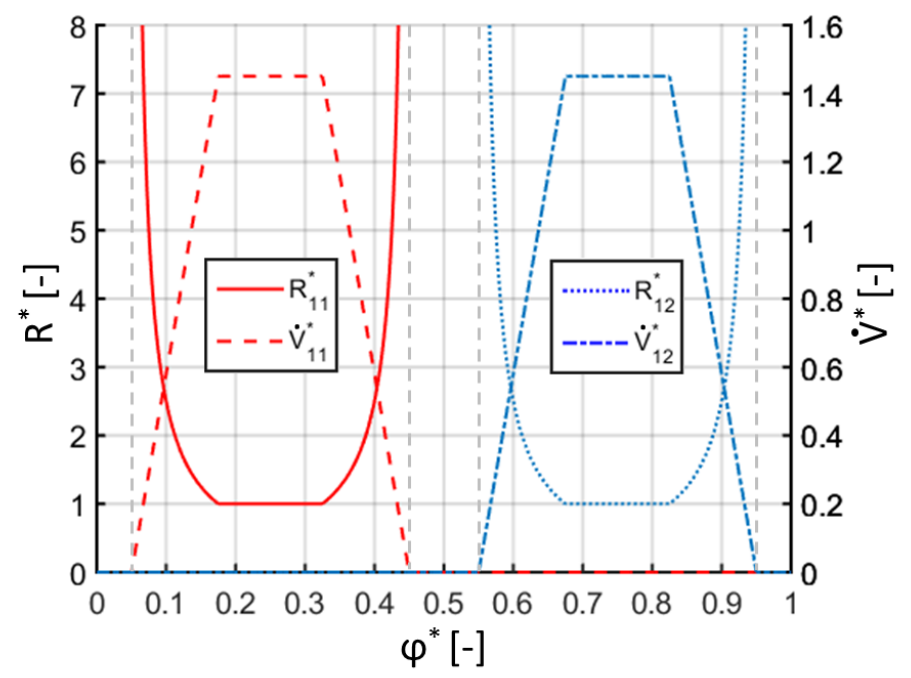

Figure 11: Resistance and flow rate as functions of the normalized rotational angle in bed one during an AMR cycle with all other resistors set to zero. The resistances are normalized with the values corresponding to fully open poppet valves, i.e. $R_{i j}^{*}(\phi)=R_{i j}(\phi) / R_{i j, \text { open }}$. The flow rates are normalized with the average non-zero flow rates in both directions in the bed, i.e. $\dot{V}_{i j}^{*}(\phi)=$ $\dot{V}_{i j}(\phi) / \dot{V}_{j, \text { avg }}$.

cycle. This implies that if bed one were tested separately in each direction, corresponding to $R_{i j}=0, i \neq 1$ in Figure 10, the resistance would decrease/increase hyperbolically between infinity and finite values, $R_{1 j \text {,open }}$, while the flow would ramp up/down linearly, as indicated in Figure 11. The total resistances in the two directions are then:

$$
R_{j, \mathrm{tot}}(\phi)=\left(\sum_{i=1}^{n} \frac{1}{R_{i j}(\phi)}\right)^{-1} .
$$

A constant pressure above the atmosphere, $P_{1}$, is set after the pump, and the circuit is "grounded" (open to the ambient pressure) before the pump, i.e. the total pressure drop is $\Delta P_{\text {tot }}=P_{1}$, giving a total volumetric flow rate, $\dot{V}_{\text {tot }}$ of 


$$
\dot{V}_{\text {tot }}(\phi)=\frac{P_{1}}{R_{1, \text { tot }}(\phi)+R_{2, \text { tot }}(\phi)} .
$$

From this, the intermediate pressure, $P_{2}$, can be expressed as

$$
P_{2}=R_{2, \text { tot }}(\phi) \dot{V}_{\text {tot }}(\phi) \text {. }
$$

With $\Delta P_{1}=P_{1}-P_{2}$ and $\Delta P_{2}=P_{2}-P_{3}$, the flow rates in each bed as functions of $\phi$ are then

$$
\dot{V}_{i j}(\phi)=\frac{\Delta P_{j}}{R_{i j}(\phi)} .
$$

To illustrate the flow profiles in an actual multi-bed machine, measured resistances in the prototype shown in Figure 1 are used, see Table 2.

\begin{tabular}{|c|ccccccccccc|}
\hline$i$ & 1 & 2 & 3 & 4 & 5 & 6 & 7 & 8 & 9 & 10 & 11 \\
\hline$R_{i 1}$ & 0.84 & 0.83 & 0.87 & 0.92 & 0.89 & 0.90 & 0.92 & 0.83 & 0.85 & 0.79 & 0.88 \\
$R_{i 2}$ & 1.06 & 1.02 & 1.14 & 1.06 & 1.00 & 1.12 & 1.03 & 1.02 & 1.13 & 1.12 & 1.00 \\
\hline$u_{i}$ & 3.1 & -0.2 & 5.4 & -7.6 & -7.7 & 3.0 & -7.3 & -0.8 & 6.5 & 12.5 & -6.8 \\
\hline
\end{tabular}

Table 2: Measured flow resistances, $R_{i j}$, in bar min $\mathrm{L}^{-1}$ and resulting calculated flow unbalances, $u_{i}$, in percent.

The resistances in a bed in one direction, say hot to cold, is measured by only having this particular bed open to flow in that direction. By means of pressure gauges, the pressure drop over the bed is measured and the corresponding flow rate is measured by an in-line flow meter. The signals are then used simultaneously in a LabView program to calculate the resistance. Due to the accuracies of the gauges, the uncertainty on the resistance measurements is $2 \%$. Although this is quite significant compared to the variations between the beds, these values are used as examples in the present analysis. From these resistances, the corresponding flow rates are calculated using Eqs. 8-11, with the inlet pressure set to $P_{1}=2$ bar, and the corresponding unbalances are given in Table 2. As an example, the resulting flow profiles are plotted for bed number four in Figure 12 (solid lines), with the values normalized as in Figure 11. In this case, an unbalance of $u=-7.54 \%$ is present. In the same figure, the profiles are plotted in the case where the average 


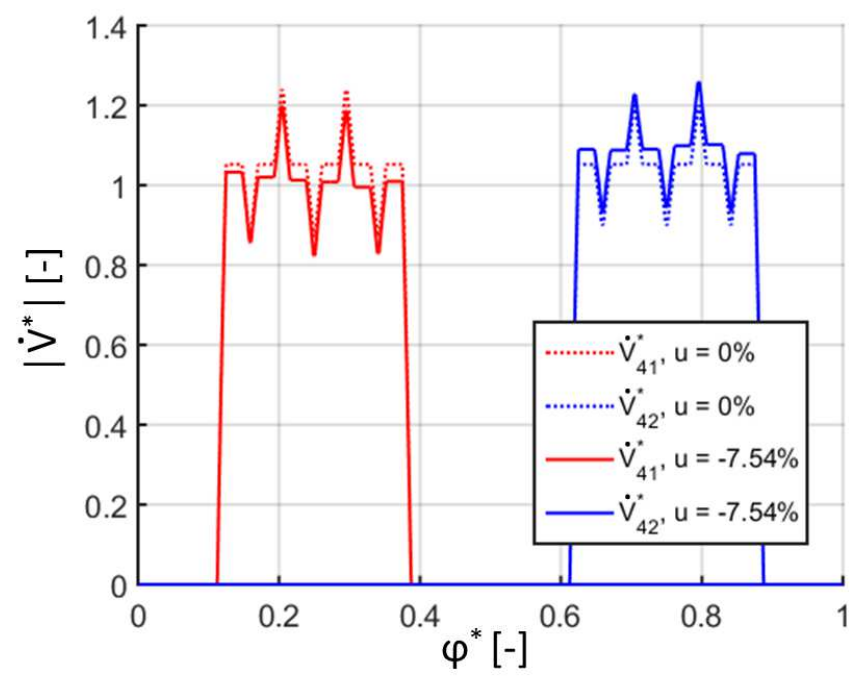

Figure 12: Calculated flow profiles with and without unbalance of bed number four in the eleven bed prototype.

resistance in the two directions are used respectively, thereby eliminating the unbalance.

The actual cam profile has steep ramps $\left(\phi_{\mathrm{r}}^{*}=0.05\right)$ and a fully open fraction of $\phi_{\mathrm{f}}^{*}=0.5$. It is seen that during the fully open periods, the flow profile has a jagged shape. This is explained by the number of beds open to flow in the two directions, which varies with the rotation angle. All beds have the same number of spikes and depressions at the same rotational angles relative to the individual beds. In general, the number and magnitudes of spikes and depressions for rotary multi-bed machines are functions of the total number of beds, number of cams per revolution and the cam profiles, which should be taken into consideration when designing such systems. Modeled flow profile spikes and depressions are in good agreement with experimental results, see (9).

It should be noted that the flow rate as function of $\phi$ is evaluated at steady flow conditions. During AMR operation the spikes and depressions may be dampened by the means of a pressure vessel. Due to asymmetries in the design, it is clear from Table 2 that the resistance is higher in the cold-to-hot than in the hot-to-cold direction, with average resistances of $R_{i 1 \text {,avg }}=0.86$ 
bar min $\mathrm{L}^{-1}$ and $R_{i 2 \text {,avg }}=1.06$ bar $\min \mathrm{L}^{-1}$, respectively. The standard deviations in flow resistances in the two directions are: $\sigma_{\mathrm{R}, 1}=4.0 \%$ and $\sigma_{\mathrm{R}, 2}=$ $5.4 \%$, respectively. This offset between resistances in the two directions does not in itself give rise to unbalanced flow. Furthermore, if there is a variation in resistance between the beds, but it is independent of the flow direction, i.e. $R_{i 1}=R_{i 2}$, no flow unbalances are present, although this leads to a variation in flow rates between beds. Only in the case where the varying resistances become direction-dependent, the flow in the beds becomes unbalanced.

\section{Effect on multi-bed AMR performance}

The 1D AMR model described in Section 3 has been used with flow profiles calculated by the flow model described in Section 4 to investigate the impact of varying flow resistances on multi-bed AMRs. We have modeled the rotary prototype with these flow profiles with and without the spikes and depressions while keeping the average flow constant. We found no significant impact of the "jaggedness" in the present case.

The impact of direction dependent flow resistances has been investigated by modeling a number of cases of AMR machines containing eleven beds, similar to the described rotary prototype. This was done as described in the following.

A data set containing cooling power and heat rejection for a bed was calculated with the AMR model with a frequency of $f=1 \mathrm{~Hz}$. Here, the flow rate was varied from $0.9 \mathrm{~L} \mathrm{~min}^{-1}$ to $1.1 \mathrm{~L} \mathrm{~min}^{-1}$ in steps of $0.01 \mathrm{~L} \mathrm{~min}^{-1}$ and the unbalance was varied from $-20 \%$ to $20 \%$ in steps of $1 \%$. The results are shown in Figures 13 and 14.

Next, resistance combinations corresponding to a number of hypothetical eleven-bed machines have been generated with random normally distributed flow channel resistances with mean values of $R_{i 1 \text {,avg }}=R_{i 2 \text {,avg }}=1$ bar min $\mathrm{L}^{-1}$ and standard deviations, $\sigma_{R}$, varied from $0 \%$ to $5 \%$ in steps of $1 \%$, to stay consistent with the orders of magnitudes observed in the experiment. The inlet pressure was set to $P_{1}=2$ bar. The flow rates and unbalances corresponding to this were calculated with the flow model in all cases. For each of these hypothetical machines, the flow rates and unbalances of all beds correspond to cooling powers and heating powers which are found by interploation in the modeled AMR dataset shown in Fig. 13 and 14. 


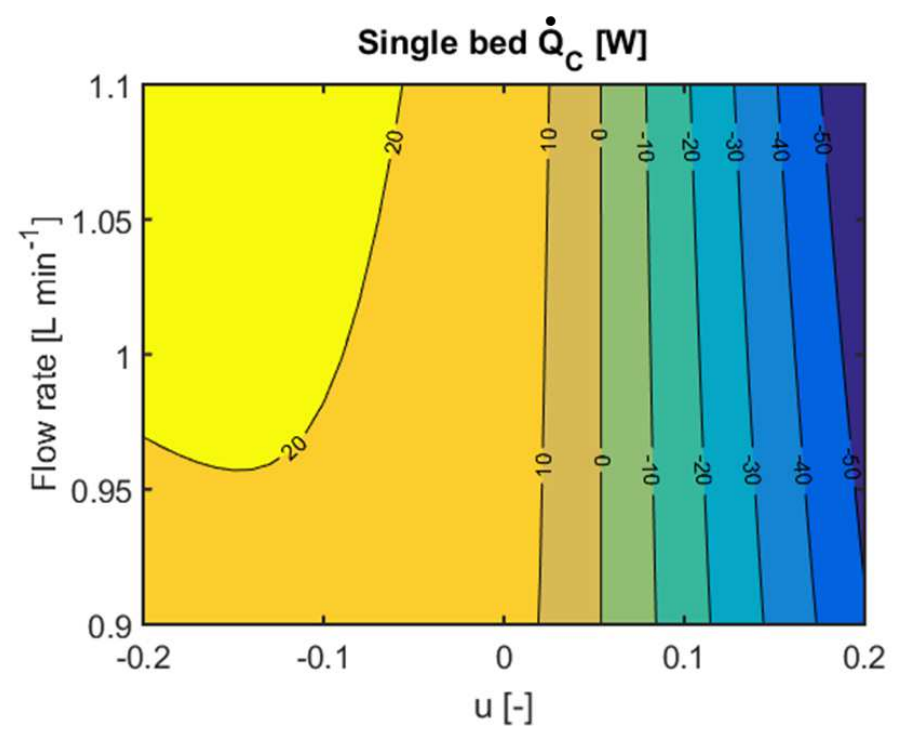

Figure 13: Modeled single bed cooling power of the rotary prototype as a function of unbalance fraction and flow rate.

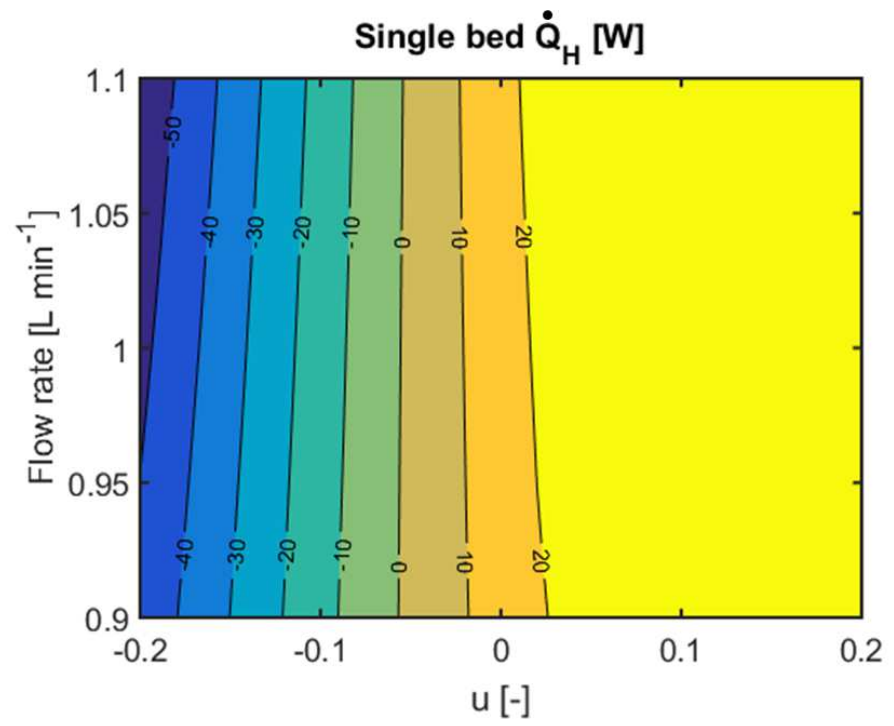

Figure 14: Modeled single bed heat rejection as a function of unbalance fraction and flow rate. 


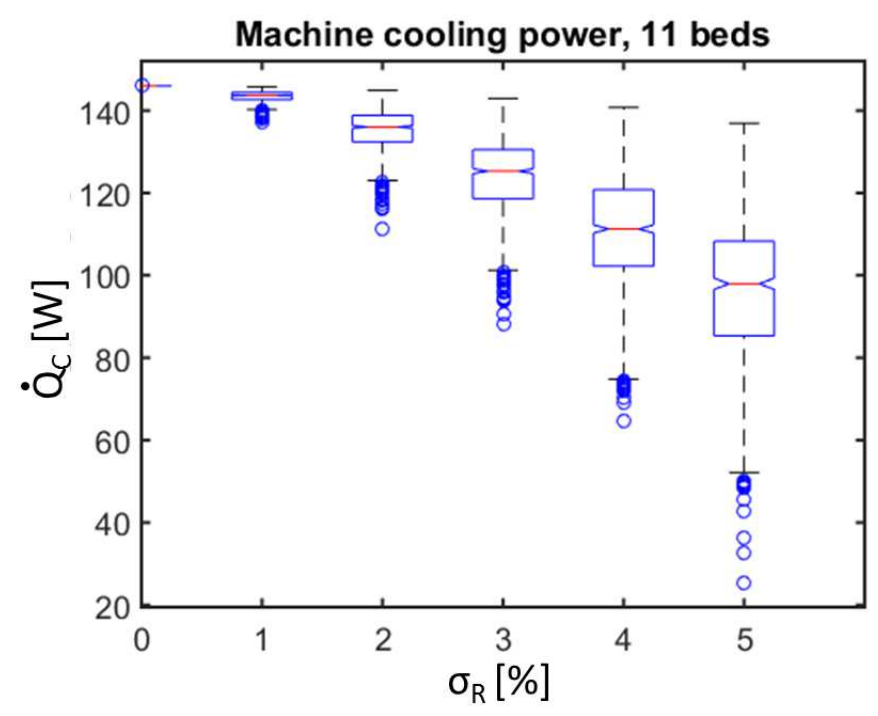

Figure 15: Distributions of cooling powers from 1000 imaginary prototypes with eleven beds plotted at different standard deviations in the flow resistances

The result of this modeling exercise is a resulting cooling power and COP for 1000 randomly generated devices for each standard deviation of flow resistance. The resulting cooling powers and COPs are shown as box and whiskers plots in Figures 15 and 16. In these plots, the $25^{\text {th }}$ and $75^{\text {th }}$ percentiles are indicated by the lower and upper box edges respectively, while the median is indicated by a central mark and necking of the boxes. The whiskers extend to the most extreme values not considered outliers, as these are plotted individually. The plot indicates that a device with even relatively small variation in the flow resistance in the regenerator beds can exhibit a large range of possible device performance. It also indicates that some combinations fortuitously perform better than others.

It is clear from the figures that the performance is likely to decrease significantly as the standard deviation of the channel flow resistances increases, causing unbalanced flow in the beds. In this case, the median of the cooling powers decreased by more than $30 \%$ at a standard deviation of $5 \%$ of the resistances compared to a perfect distribution of flow resistances. The median COP dropped by almost $50 \%$. These trends are in agreement with the case 


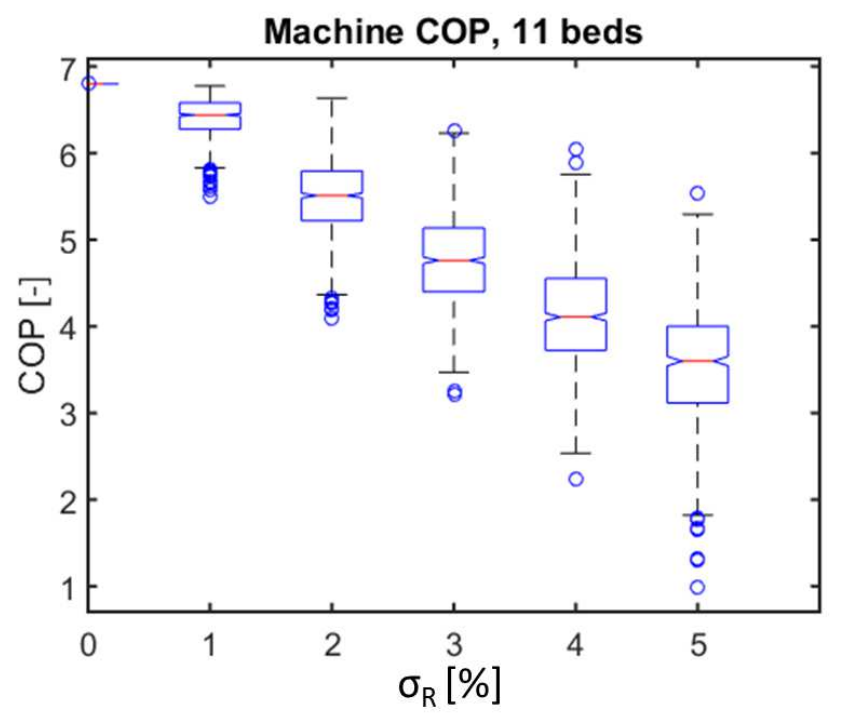

Figure 16: Distributions of COPs from 1000 imaginary prototypes with eleven beds plotted at different standard deviations in the flow resistances

of the two-bed device model presented in Section 4.

For the actual prototype, the flow resistances were all set to 0.92 bar min $\mathrm{L}^{-1}$ in the hot-to-cold direction and 1.14 bar $\mathrm{min}^{-1}$ in the cold-to-hot direction by the adjustment valves, to eliminate the flow unbalances within the measurement uncertainty of $2 \%$. This resulted in a temperature span of 27.3 $\mathrm{K}$ for an experiment similar to the one shown in Figure 3, where the span was $16.4 \mathrm{~K}$ in the unbalanced case. This supports the prediction of strong impact on AMR performance of flow balancing. In the AMR experiments, which are without an applied cooling load, the effects are only evident via the generated no-load temperature spans. With the current setup it is not feasible to do a direct comparison between the modeled effects of resistance variations on cooling powers and COPs with those predicted by the calculations. This would require a setup with a very fine control over the resistances of the beds, as even small variations may result in large impacts as the present analysis suggests. 


\section{Conclusion}

It is shown by a theoretical study based on $1 \mathrm{D}$ AMR modeling that unbalanced heat transfer fluid flow in the regenerators can drastically deteriorate the performance of AMR machines. This is shown to be the case for a modeled device with two coupled regenerators and a fluid displacer imposing an unbalance. For rotary multi-bed devices, it is shown through flow modeling, that variations in the flow resistances between the flow channels transporting flow in and out of the regenerator beds give rise to unbalanced flow in the beds. By modeling a large number of cases with varying standard deviations on the resistances of the flow channels, corresponding to an actual elevenbed prototype, it is concluded that the performance in terms of cooling power and COP is likely to deteriorate as much for the multi-bed machine with a standard variation in resistances of $5 \%$ as it did in the modeled case of the two-bed device with an imposed unbalance of $5 \%$. The results are supported

by observed negative impacts on the temperature span by flow resistance variations in experiments with the rotary prototype.

\section{Acknowledgements}

The authors would like to acknowledge the ENOVHEAT project which is funded by Innovation Fund Denmark (contract no 12-132673). 


\section{References}

[1] A. Kitanovski, J. Tusek, U. Tomc, U. Plaznik, M. Ozbolt, A. Poredos, Magnetocaloric Energy Conversion From Theory to Applications, Springer International Publishing, Switzerland, 2015, pp. 269-327.

[2] C. Zimm, A. Jastrab, V. Sternberg, V. Pecharsky, K. Gschneidner Jr., M. Osborne, I. Anderson, Description and performance of a near room temperature magnetic refrigerator, Adv. Cryog. Eng. 43 (1998) 17591766.

[3] A. M. Rowe, J. A. Barclay. Design of an active magnetic regenerator test apparatus, in AIP Conference Proceedings, 613 (2002) 995-1002.

[4] D. S. Arnold, A. Tura, A. Ruebsaat-Trott, A. Rowe, Design improvements of a permanent magnetic active magnetic refrigerator, Int. J. Refrigeration 37 (2014) 99-105.

[5] S. Jacobs, J. Auringer, A. Boeder, J. Chell, L. Komorowski, J. Leonard, S. Russek, C. Zimm, The performance of a large-scale rotary magnetic refrigerator, Int. J. Refrigeration 37 (2014) 84-91.

[6] D. Eriksen, K. Engelbrecht, C. R. H. Bahl, R. Bjørk, K. K. Nielsen, A. R. Insinga, N. Pryds, Design and experimantal tests of a rotory active magnetic regenerator prototype, Int. J. Refrigeration (2015). doi: 10.1016/j.ijrefrig.2015.05.004, available online (2015): http://authors.elsevier.com/sd/article/S0140700715001334

[7] R. Bjørk, C. R. H. Bahl, A. Smith, N. Pryds, Review and comparison of magnet designs for magnetic refrigeration, Int. J. Refrigeration 33 (2010) 437-448.

[8] D. Eriksen, K. Engelbrecht, C. R. H. Bahl. An active magnetic regenerator device. International Patent Application WO 2015/118007 A1, 2015.

[9] D. Eriksen, K. Engelbrecht, C. Bahl, R. Bjørk, K. Nielsen, A. Insinga, S. Dall'Olio, N. Pryds, Experimental studies with an active magnetic regenerating refrigerator, Accepted for publication in: Proceedings of The $24^{\text {th }}$ IIR International Congress of Refrigeration, ICR2015, Yokohama, Japan, 2015. 
[10] C. Zimm, S. Russek, Near room temperature magnetic refrigeration: The path to applications. in: P. W. Egolf (Ed.),Proceedings of the 3rd Inernational Conference on Magnetic Refrigeration at Room Temperature, Des Moins, Iowa, USA, 2009, pp. 267-274.

[11] A. Tura, A. Rowe, Permanent magnet magnetic refrigerator design and experimental characterization, Int. J. Refrigeration 34 (2011) 628-639.

[12] K. Engelbrecht, A numerical model of an active magnetic regenerator refrigerator with experimental validation, $\mathrm{PhD}$ thesis, University of Wisconsin, Madison, 2008.

[13] J. Tusek, A. Kitanovski, S. Supan, I. Prebil, A. Poredos, Permanent magnet magnetic refrigerator design and experimental characterization, Appl. Therm. Eng. 53 (2013) 57-66.

[14] J. Tusek, A. Kitanovski, U. Tomc, C. Favero, A. Poredos, Experimental comparison of multi-layered La-Fe-Co-Si and single layered Gd active magnetic regenerators for use in a room temperature magnetic refrigerator, Int. J. Refrigeration 37 (2014) 117-126.

[15] C. Aprea, A. Greco, A. Maiorino, R. Mastrullo, A. Tura, Initial experimental results from a rotary permanent magnet magnetic refrigerator, Int. J. Refrigeration 43 (2014) 111-122.

[16] C. Aprea, A. Greco, A. Maiorino, GeoThermag: A geothermal magnetic refrigerator, Int. J. Refrigeration 59 (2015) 75-83.

[17] C. Aprea, A. Greco, A. Maiorino, C. Masselli, The energy performances of a rotary permanent magnet magnetic refrigerator, Int. J. Refrigeration 61 (2016) 1-11.

[18] J. Lozano, Designing a rotary magnetic refrigerator, PhD thesis, Federal University of Santa Catarina, Florianopolis, 2015.

[19] Z. G. Zheng, H. Y. Yu, X. C. Zhong, Z. W. Liu, D. C. Zeng, S. H. You, A practical model for performance analysis of a reciprocating room temperature magnetic regenerator, in: A. Poredos, A. Sarlah (Ed.),Proceedings of the 2nd Inernational Conference on Magnetic Refrigeration at Room Temperature, Portoroz, Slovenia, 2007, pp. 223-228. 
[20] T. F. Petersen, N. Pryds, A. Smith, J. Hattel, H. Schmidt, H. J. Høgaard-Knudsen, Two-dimensional mathematical model of a reciprocating room-temperature active magnetic regenerator. Int. J. Refrigeration 31 (3) (2008) 432-443.

[21] K. K. Nielsen, C. R. H. Bahl, A. Smith, R. Bjørk, N. Pryds, J. Hattel, Detailed numerical modeling of a linear parallel-plate active magnetic regenerator. Int. J. Refrigeration 32 (6) (2009) 1478-1486. 
